\title{
Experiences with a technique of neuroleptanalgesia for bronchography
}

\author{
H. M. STEVENSON, S. K. PANDIT, J. W. DUNDEE, \\ S. MCDOWELL, and J. D. MORRISON \\ Departments of Thoracic Surgery and Anaesthetics, Royal Victoria Hospital, Belfast, Northern Ireland
}

The use of a mixture of $2 \mathrm{mg}$ phenoperidine and $5 \mathrm{mg}$ droperidol as an adjunct to topical anaesthesia for bronchography, with or without prior bronchoscopy, is reported in 100 adult patients. Given slowly over 2 to 10 minutes this produces good operating conditions in the majority of patients. However, if parenteral pethidine or diazepam are used as premedication, patients may be too drowsy to co-operate with changes in posture. In the absence of excessive sedation respiratory depression will respond to the simple expedient of asking the patient to breathe. It is recommended that atropine alone be given as premedication, perhaps with oral diazepam in apprehensive patients. Despite the good operating conditions most patients remembered the procedure and half of them found it to be unpleasant.

The ideal conditions for performance of bronchography may be summarized as follows:

1. The patient should remain conscious and be able to co-operate throughout the procedure.

2. At the same time he should be sufficiently sedated so that what is an essentially unpleasant experience, especially where bronchoscopy precedes the bronchogram, can be more readily tolerated.

3. The cough reflex should be abolished without concomitant respiratory depression and without depriving the patient of his ability to cough voluntarily at the end of the procedure.

No one technique presently in use can guarantee all of these factors. Local analgesia, alone or in combination with light sedation from barbiturate or opiate, is commonly used in adults and older children, but persistence of an active cough reflex following instillation of the contrast medium often contributes to the patient's discomfort and may result in poor pictures. Too heavy sedation or deep general anaesthesia, on the other hand, may result in a patient without cough reflex but with gravely impaired respiratory activity which may persist beyond the duration of the examination. The patient may also be unable to co-operate in positioning for radiography, and be subject to cardiovascular disturbance secondary to postural change.

The introduction of the technique of neuroleptanalgesia (De Castro and Mundeleer, 1959) seemed to offer the possibility of a more suitable sedation to supplement local analgesia for bronchography (Brown, 1969). Neuroleptanalgesia may be defined as profound sedation produced by combination of a powerful opiate and a neuroleptic (or major tranquillizer such as droperidol, haloperidol or chlorpromazine) drug in which the patient remains conscious and fully rousable, although catatonic and apparently tranquil and free from pain. Stability of the cardiovascular system during neuroleptanalgesia is claimed to be remarkable, even during major degrees of tilting (Brown, Horton, and MacRae, 1963). However, respiratory depression does occur, although this can often be managed simply by reminding the patient to breathe from time to time.

A neuroleptanalgesia technique involving the use of the opiate phenoperidine (Operidine) and the tranquillizer droperidol (Droleptan) has been evaluated in a series of patients undergoing bronchography with, and without, bronchoscopy.

\section{METHOD}

The series consisted of 100 adults undergoing bronchography, mostly as outpatients.

Premedication was entirely omitted in 38 patients; 39 were given diazepam, $10 \mathrm{mg}$, and 17 were given pethidine, $50 \mathrm{mg}$, with or without atropine, $0.6 \mathrm{mg}$ (Table I). Premedication, when used, was administered 30 to 90 minutes before the patient arrived in the operating room. On arrival, the patients were given atropine, $0.6 \mathrm{mg}$ intravenously (if not included in the premedication), followed by droperidol, $5 \mathrm{mg}$, and 
T A B LE I

CLASSIFICATION OF OPERATIVE CONDITIONS AND INCIDENCE OF RESPIRATORY DEPRESSION, EXPRESSED AS PERCENTAGES, FOR EACH PREMEDICATION GROUP

\begin{tabular}{|c|c|c|c|c|c|c|c|}
\hline \multirow{2}{*}{$\begin{array}{l}\text { Premedication } \\
\text { Atropine, } 0.6 \mathrm{mg} \text {, plus }\end{array}$} & \multirow{2}{*}{$\begin{array}{l}\text { No. of } \\
\text { Patients }\end{array}$} & \multicolumn{3}{|c|}{ Clinical Condition ( $\%$ of patients) } & \multicolumn{3}{|c|}{ Respiratory Depression ( $\%$ of patients) } \\
\hline & & $\begin{array}{l}\text { Unco- } \\
\text { operative }\end{array}$ & Co-operative & Too Drowsy & $\begin{array}{l}\text { Responded } \\
\text { to Command }\end{array}$ & $\begin{array}{l}\text { Failed } \\
\text { to Respond }\end{array}$ & $\begin{array}{l}\text { Needed } \\
\text { Antidote }\end{array}$ \\
\hline $\begin{array}{l}\text { Nil } \\
\text { Pethidine, } 50 \mathrm{mg} \text { I.M. } \\
\text { Diazepam, } 10 \mathrm{mg} \text { I.M. } \\
\text { Diazepam, } 10 \mathrm{mg} \text { orally } \\
\text { Other }\end{array}$ & $\begin{array}{r}38 \\
17 \\
16 \\
23 \\
6\end{array}$ & $\begin{array}{l}\mathbf{5} \\
\mathbf{0} \\
\mathbf{0} \\
4 \\
\mathbf{0}\end{array}$ & $\begin{array}{l}92 \\
76 \\
37 \\
92 \\
33\end{array}$ & $\begin{array}{r}3 \\
24 \\
63 \\
4 \\
67\end{array}$ & $\begin{array}{r}100 \\
88 \\
56 \\
96 \\
33\end{array}$ & $\begin{array}{r}0 \\
12 \\
44 \\
4 \\
67\end{array}$ & $\begin{array}{r}0 \\
12 \\
19 \\
4 \\
17\end{array}$ \\
\hline Total & 100 & 3 & 77 & 20 & 86 & 14 & 7 \\
\hline
\end{tabular}

phenoperidine, $2 \mathrm{mg}$ intravenously, given over 2 to 10 minutes. At this time, if the respiratory rate became too slow, the patient was reminded to breathe. The lips, mouth, and pharynx were sprayed lightly with $4 \%$ lignocaine and, when the tongue was numb, the larynx and upper trachea were similarly sprayed with the aid of a Macintosh laryngoscope and a Forrester spray. The total dose of lignocaine used did not usually exceed $4 \mathrm{ml}$ of the $4 \%$ solution.

If bronchoscopy was to be performed, it was carried out as soon as the local anaesthesia was established. The contrast medium was then instilled through a catheter inserted in the upper trachea and the patient was positioned for radiography. Throughout the procedure the patient was reminded to breathe when necessary and was encouraged not to cough. After satisfactory pictures had been obtained he was instructed to cough to clear the contrast medium from the tracheobronchial tree. Blood pressure and pulse rate were monitored at minute intervals throughout by conventional means. Occasionally it was necessary to give supplementary increments of $2.5 \mathrm{mg}$ phenoperidine to maintain the desired state of sedation.

In 27 patients, arterial blood samples were drawn before starting the anaesthetic procedure and again after completion of the radiography; $\mathrm{pH}$, carbon dioxide, and oxygen tensions were estimated using the standard Astrup technique. Where possible, patients were visited several times during the postoperative period and their opinion of the procedure and memory of individual events were noted.

\section{RESULTS}

(1) OPERATIVE CONDITIONS It can be seen from Table I that 77 of the 100 patients were judged to be capable of co-operating during the procedure, in that they needed no physical assistance to maintain the postures required for bronchography. Of the remainder, 3 were conscious but unwilling or unable to co-operate while 20 were too drowsy to do so. All but one of those who were too drowsy had been given either diazepam or pethidine as premedication.
(2) RESPIRATORY DEPRESSION Respiratory depression of a degree which failed to respond to instructing the patient to breathe was seen in 14 patients, in 7 of whom the condition persisted long enough for it to be considered necessary to administer a specific opiate antagonist. Again it is notable that those patients who developed significant respiratory depression were those who had been given premedication of pethidine or diazepam. The average pH and blood gas levels are shown in Table II. The degree of residual depression from the opiate was shown by a mean rise in $\mathrm{PCO}_{2}$ from 39.0 to $42.0 \mathrm{mmHg}$ along with a fall in $\mathrm{pH}$ from 7.39 to $7 \cdot 35$. There was a mean fall of 18.3 in the $\mathrm{Po}_{2}$ from $77 \cdot 8$ to $59 \cdot 5 \mathrm{mmHg}$.

\section{T A B L E I I}

MEAN PH AND BLOOD GAS LEVELS IN 27 PATIENTS BEFORE AND AFTER BRONCHOGRAPHY

\begin{tabular}{c|c|c}
\hline & Pre-induction & Post-radiography \\
\hline & 77.8 & $59 \cdot 5$ \\
$\mathrm{PaO}_{2}$ & 39.0 & 42.0 \\
$\mathrm{pH}$ & 7.39 & 7.35 \\
\hline
\end{tabular}

(3) SUBJECTIVE APPRECIATION Only three patients appeared to be disturbed by either bronchoscopy or bronchography and the anaesthetist's impression was that 88 patients were completely comfortable during bronchography. Several patients complained of dizziness and an unpleasant feeling during the actual injection of the neuroleptic drug. This incidence was reduced by administering premixed droperidol and phenoperidine instead of giving the droperidol first. However, of 90 patients questioned after the procedure, $9 \%$ stated that the examination had been painful and a further $46 \%$ found it to be distinctly unpleasant. In 84 patients, the degree of anterograde amnesia was determined 6 or 24 hours later. The results as shown in Table III are disappointing. However, there was a higher 
T A B L E I I I

INCIDENCE OF ANTEROGRADE AMNESIA IN 84 PATIENTS

\begin{tabular}{l|c|c}
\hline \multirow{2}{*}{ Group } & \multicolumn{2}{|c}{ Percentage Incidence } \\
\cline { 2 - 3 } & Complete Amnesia & Partial Amnesia \\
\hline No premedication & 0 & 4 \\
Opiate & 12 & 6 \\
Diazepam & 2 & 18 \\
\hline
\end{tabular}

incidence of amnesia in those patients who had been given a premedication, either pethidine or diazepam.

(4) Miscellaneous In three chronic alcoholics included in this series the technique proved perfectly adequate, but the dosage of droperidol and phenoperidine had to be increased.

In one patient the injection of droperidol/ phenoperidine mixture was followed by acute spasticity, making ventilation difficult to the point of requiring the use of a muscle relaxant. One patient developed an acute extrapyramidal excitation with the typical pill-rolling agitation of parkinsonism, and another patient complained of transient diplopia during injection of the mixture.

\section{DISCUSSION}

In the majority of cases the technique described fulfils the first of the conditions necessary for the ideal performance of bronchography, i.e., the patient remains conscious and fully co-operative. Not only does this contribute to the ease with which bronchography is performed but it also ensures that the attendants are not unnecessarily exposed to radiation by having to support the patient. Twenty patients were too drowsy to cooperate and 19 of these had been given sedative premedication. It might be better either to omit premedication entirely or, alternatively, to limit it to small doses of diazepam, preferably given orally.

One of the well-recognized drawbacks of neuroleptanalgesia using droperidol is that an apparently calm and comfortable patient may later complain of considerable subjective disturbance (Morrison, 1969). This phenomenon occurred in this series in which, despite the anaesthetist's assessment of $88 \%$ good acceptance of the technique by the patient, more than half the patients later said that it was an unpleasant or painful experience. This is the major drawback of this neuroleptanalgesic technique and perhaps the most difficult to deal with. One possible solution would be to include a drug, such as diazepam, which would induce some degree of amnesia for the procedure. However, attempts to do this by including diazepam as a premedication were frustrated by the high incidence of excessive drowsiness. It should be noted that the maximal effects of droperidol and phenoperidine occur some 10 to 15 minutes after intravenous injection (Morrison, 1970): it may be that in some of these patients supplementary doses of neurolept mixture were injected before the full effect of the initial dose had developed. More careful attention to this aspect of the technique might have reduced the number of patients who became too drowsy, irrespective of what premedication they had been given.

Coughing rarely occurred during instillation of the contrast medium and, although suppression of ventilation was a universal effect, in almost all cases this was managed simply by instructing the patient to breathe. In those patients who are too drowsy to obey, the respiratory depression responds readily to any specific opiate antagonist, e.g., levallorphan. The degree of residual respiratory depression from phenoperidine, whose depressant activity is maximal at 10 minutes and has begun to wane by 30 minutes following injection (Prys-Roberts and Kelman, 1967), is reflected in the slight rise in $\mathrm{PCO}_{2}$ of arterial blood. The fall in $\mathrm{PaO}_{2}$ may be due in part to the persistence of contrast material in the lungs. It is not considered that the respiratory effects of neuroleptanalgesia, provided that they are recognized, are any contra-indication to its use in bronchography. However, in this respect, it would be unwise to attempt to use this technique in circumstances where facilities for ventilatory assistance are not available; similarly, it cannot be recommended for single-handed use unless the operator is fully capable of securing the airway and taking over ventilation, should profound respiratory depression occur. Very rarely a transient hyperspastic state of the respiratory muscles follows the administration of phenoperidine (Jenkins and Das, 1966) and this can best be managed by use of a short-acting muscle relaxant.

It is believed that the technique described herein, although not perfect, goes a long way towards fulfilling the ideal as presented in the introduction: it has proved safe and has given excellent results in terms of the quality of the bronchograms. Its least satisfactory facet is that rather more than half the patients still found the experience of bronchography unpleasant.

\section{REFERENCES}

Brown, A. S. (1969). Neuroleptanalgesia. In Newer Intravenous Anesthetics, edited by R. S. J. Clarke, p. 159. International Anesthesiology Clinics, vol. 7, no. 1. Little, Brown, Boston. 
_, Horton, J. M., and MacRae, W. R. (1963). Anaesthesia for neurosurgery. The use of haloperidol and phenoperidine with light general anaesthesia. Anaesthesia, 18, 143.

De Castro, J., and Mundeleer, P. (1959). Anesthésie sans barbituriques: la neuroleptanalgésie. Anesth. Analg. Réanim., 16, 1022.

Jenkins, A. V., and Das, B. (1966). The use of phenoperidine in thoracic surgery. Anaesthesia, 21, 51.
Morrison, J. D. (1969). Drugs used in neuroleptanalgesia. In Newer Intravenous Anesthetics, edited by R. S. J. Clarke, p. 141. International Anesthesiology Clinics, vol. 7, no. 1. (1970). Studies of drugs given before anaesthesia. XXII: Phenoperidine and fentanyl, alone and in combination with droperidol. Brit. J. Anaesth., 42, 1119.

Prys-Roberts, C., and Kelman, G. R. (1967). The influence of drugs used in neuroleptanalgesia on cardiovascular and ventilatory function. Brit. J. Anaesth., 39, 134. 